[RAdiocarbon, Vol. 15, No. 3, 1973, P. 488-492]

\title{
GLASGOW UNIVERSITY RADIOCARBON MEASUREMENTS VII
}

\author{
M. S. BAXTER and J. G. FARMER*
}

Chemistry Department, The University, Glasgow, G12 8QQ

INTRODUCTION

This list presents results obtained during 1971-1972 and is a continuation of research evaluating natural $\mathrm{C}^{14}$ levels for which data have been published previously (Baxter et al., 1969; Baxter and Walton, 1970; Farmer et al., 1972). The results of these studies are presented as $\delta \mathrm{C}^{14}$ and $\Delta$ values based on age-corrected activities, although this correction is very small. Errors quoted are $l_{\sigma}$ counting uncertainties only. Pretreatment procedures are outlined in the text and analytical methods are essentially unchanged. Gas proportional counting of $\mathrm{CH}_{4}$ in a $0.5 \mathrm{~L}$ detector is employed (Baxter et al., 1969). Mass spectrometric analyses are performed to a precision of $0.1 \% \circ( \pm 2 \sigma)$ on a V.G. Micromass 602B stable isotope mass spectrometer.

\section{ACKNOWLEDGMENTS}

This work is supported by grants from the Natural Environment Research Council. We wish to thank the individuals and organizations who supplied sample materials. We are also grateful to T. D. B. Lyon for supervision of mass-spectrometric techniques and to A. J. A. Brown for efficient technical assistance.

\section{SAMPLE DESCRIPTIONS}

\section{TREE-RING SAMPLES}

An integral part of the research program was the study of "bomb" $\mathrm{C}^{14}$ within recent tree rings to assess the value of different extraction techniques in pretreating wood for $\mathrm{C}^{14}$ analysis. Samples were single tree rings from a Scottish Silver Fir (Abies nobilis) planted in 1937 (felled 1970) in Glengarry Forrest (57 $7^{\circ} \mathrm{N}$ Lat, $5^{\circ} \mathrm{W}$ Long), Invernessshire. Acetone and petroleum ether extractions consisted of 24-hr Soxhlet extractions of wood shavings in acetone and 40/60 petroleum ether respectively, followed by drying at $100^{\circ} \mathrm{C}$ for $24 \mathrm{hr}$. Acid/base pretreatment consisted of successive 4-hr boilings in $4 \% \mathrm{HCl}$ and $1 \% \mathrm{NaOH}$. Cellulose fractions were obtained by bleaching the ether-extracted wood and were charred at $500^{\circ} \mathrm{C}$ prior to combustion. The lignin fraction was obtained from the post-petroleum ether residue by the $72 \% \quad \mathrm{H}_{2} \mathrm{SO}_{4}$ method.

Study of 19th century atmospheric $\mathrm{C}^{14}$ concentrations in the $\mathrm{N}$ hemisphere (Farmer et al., 1972) is based on further analyses of charred cellulose fractions from annual rings of an Oak (Quercus robur) planted in 1810 (felled in 1970) at Russell's Enclosure, Forest of Dean (51 $48^{\prime}$

* Chemistry Department, Woods Hole Oceanographic Institution, Woods Hole, Massachusetts 02543 . 
N Lat, $2^{\circ} 37^{\prime}$ Long), Gloucestershire, England. Rings for 1846-1848 were not readily separable.

Natural $\mathrm{C}^{14}$ concentrations in the atmosphere of the $\mathrm{S}$ hemisphere during the 20th century were studied partly through analyses of annual rings of Radiata Pine (Pinus radiata) planted ca. 1930 (felled 1970) in Rotorua (38 $9^{\prime} \mathrm{S}$ Lat, $176^{\circ} 16^{\prime} \mathrm{E}$ Long), New Zealand. Chemical pretreatment was identical to that for the Forest of Dean Oak. The calendar year refers to the time of completion of the ring.

Tree rings, Glengarry Forest series

\begin{tabular}{lcllcc}
\hline $\begin{array}{c}\text { Sample } \\
\text { no. }\end{array}$ & Yr. & \multicolumn{1}{c}{ Fraction } & $\delta \mathrm{C}^{14} \%$ & $\delta \%$ & $\Delta \%$ \\
\hline GU-452 & 1954 & Whole wood & $+0.7 \pm 0.6$ & -28.7 & $+1.4 \pm 0.6$ \\
GU-453 & 1957 & Whole wood & $+4.4 \pm 0.6$ & -29.7 & $+5.3 \pm 0.6$ \\
GU-454 & 1958 & Whole wood & $+12.3 \pm 0.7$ & -28.8 & $+13.2 \pm 0.7$ \\
GU-455 & 1958 & Post-petrol residue & $+13.4 \pm 0.6$ & -28.1 & $+14.1 \pm 0.6$ \\
GU-456 & 1962 & Whole wood & $+34.4 \pm 0.8$ & -28.6 & $+35.4 \pm 0.8$ \\
GU-457 & 1962 & Post-petrol residue & $+34.8 \pm 0.7$ & -28.4 & $+35.7 \pm 0.7$ \\
GU-458 & 1962 & Cellulose & $+37.0 \pm 0.7$ & -27.8 & $+37.8 \pm 0.7$ \\
GU-459 & 1963 & Whole wood & $+67.0 \pm 0.7$ & -28.2 & $+68.1 \pm 0.7$ \\
GU-460 & 1963 & Post-acetone residue & $+70.1 \pm 0.9$ & -28.2 & $+71.2 \pm 0.9$ \\
GU-461 & 1963 & Post-petrol residue & $+73.6 \pm 0.9$ & -28.7 & $+74.9 \pm 0.9$ \\
GU-462 & 1963 & Cellulose & $+72.9 \pm 0.8$ & -27.3 & $+73.8 \pm 0.8$ \\
GU-463 & 1963 & Lignin & $+74.9 \pm 1.1$ & -29.0 & $+76.3 \pm 1.1$ \\
GU-464 & 1963 & Post-acid/base residue & $+72.9 \pm 0.9$ & -28.8 & $+74.3 \pm 0.9$ \\
GU-465 & 1963 & Post-acetone/ & & & \\
& & acid/base residue & $+71.5 \pm 0.9$ & -29.1 & $+72.8 \pm 0.9$ \\
GU-466 & 1964 & Whole wood & $+88.0 \pm 0.9$ & -28.7 & $+89.4 \pm 0.9$ \\
GU-467 & 1964 & Post-petrol residue & $+83.4 \pm 0.9$ & -28.6 & $+84.7 \pm 0.9$ \\
GU-468 & 1964 & Post-acetone residue & $+88.7 \pm 1.2$ & -28.3 & $+89.9 \pm 1.2$ \\
GU-469 & 1964 & Cellulose & $+81.4 \pm 0.9$ & -27.7 & $+82.2 \pm 0.9$ \\
GU-470 & 1967 & Whole wood & $+63.1 \pm 0.9$ & -28.4 & $+64.2 \pm 0.9$ \\
GU-471 & 1969 & Whole wood & $+54.6 \pm 0.8$ & -28.6 & $+55.7 \pm 0.8$ \\
GU-472 & 1969 & Post-petrol residue & $+56.3 \pm 0.8$ & -28.5 & $+57.4 \pm 0.8$ \\
GU-473 & 1969 & Cellulose & $+54.0 \pm 0.8$ & -27.7 & $+54.8 \pm 0.8$ \\
\hline & & & & & \\
\hline & & & & &
\end{tabular}

Comment: comparison of these results with atmospheric $\mathrm{C}^{14}$ levels confirms that single tree rings are valid indicators of atmospheric $\mathrm{C}^{14}$ concentrations during wood growth period. Although not conclusive from the above data, physiology and chemistry of growing wood suggests that cellulose or lignin fractions may be more valid than whole wood for some trees in studying past annual $\mathrm{C}^{14}$ levels. The lengthy laboratory procedure for chemical isolation is probably justified by resultant minimal contamination by non-contemporaneous carbonaceous material, e.g., resins (Jansen, 1970; Fairhall and Young, 1970; Olsson et al., 1972). 
Tree rings, Forest of Dean series

\begin{tabular}{llccc}
\hline Sample no. & Yr. & $\delta \mathrm{C}^{14 \%} \%$ & $\delta \mathrm{C}^{13 \%} \%$ & \multicolumn{1}{c}{${ }^{\mathrm{O}} \%$} \\
\hline GU-474 & 1835 & $+0.6 \pm 0.6$ & -24.6 & $+0.5 \pm 0.6$ \\
GU-475 & 1877 & $+1.8 \pm 0.6$ & -24.1 & $+1.6 \pm 0.5$ \\
GU-476 & 1845 & $-0.4 \pm 0.5$ & -24.9 & $-0.4 \pm 0.5$ \\
GU-477 & $1846-48$ & $-0.1 \pm 0.5$ & -24.4 & $-0.2 \pm 0.5$ \\
\hline
\end{tabular}

Comment: these results complete measurements of annual $\mathrm{C}^{14}$ levels for 1829-1865 (Farmer et al., 1972). The $\mathrm{C}^{14}$ data are highly correlated with solar activity via the expression $\Delta_{\mathrm{T}}=127.88-0.0141 \mathrm{R}_{\mathrm{T}-5}-0.0689 \mathrm{~T}$ where $\Delta_{T}=$ deviation from $0.95 \times \mathrm{NBS}$ oxalic acid $\mathrm{C}^{14}$ level at time $\mathrm{T}$ (in calendar $\mathrm{yr}$ ), $\mathrm{R}_{\mathrm{T}}=$ mean sunspot no. at time $\mathrm{T}$.

The above expression corresponds to an $\mathrm{F}$ value of 38.23 , significant at the $5 \%$ level, indicating dependence of $\mathrm{C}^{14}$ levels on solar activity and the inconstancy of annual $\mathrm{C}^{14}$ concentrations at these lats of $\mathrm{N}$ hemisphere. Further implications of the results are discussed elsewhere (Farmer and Baxter, 1972).

\section{Tree rings, Rotorua Forest series}

\begin{tabular}{lcccc}
\hline Sample no. & Yr. & $\delta \mathrm{C}^{1+\%} \%$ & $\delta \mathrm{C}^{13 \%} / \mathrm{c}$ & $\Delta \%$ \\
\hline GU-478 & 1934 & $-2.2 \pm 0.8$ & -25.7 & $-2.0 \pm 0.8$ \\
GU-479 & 1936 & $-1.4 \pm 0.6$ & -25.9 & $-1.2 \pm 0.6$ \\
GU-480 & 1938 & $-0.9 \pm 0.6$ & -24.8 & $-1.0 \pm 0.6$ \\
GU-481 & 1939 & $-1.2 \pm 0.6$ & -25.3 & $-1.1 \pm 0.6$ \\
GU-482 & 1940 & $-0.6 \pm 0.6$ & -25.3 & $-0.6 \pm 0.6$ \\
GU-483 & 1941 & $-0.9 \pm 0.6$ & -24.6 & $-0.9 \pm 0.6$ \\
GU-484 & 1942 & $-2.3 \pm 0.6$ & -25.3 & $-2.2 \pm 0.6$ \\
GU-485 & 1943 & $-1.7 \pm 0.6$ & -25.6 & $-1.6 \pm 0.6$ \\
GU-486 & 1944 & $-2.0 \pm 0.6$ & -24.9 & $-2.1 \pm 0.6$ \\
GU-487 & 1945 & $-1.6 \pm 0.6$ & -25.4 & $-1.5 \pm 0.6$ \\
GU-488 & 1949 & $-1.7 \pm 0.6$ & -24.3 & $-1.8 \pm 0.6$ \\
GU-489 & 1950 & $-2.4 \pm 0.6$ & -24.1 & $-2.6 \pm 0.6$ \\
GU-490 & 1951 & $-2.7 \pm 0.6$ & -24.1 & $-2.9 \pm 0.6$ \\
GU-491 & 1952 & $-3.5 \pm 0.8$ & -25.0 & $-3.5 \pm 0.8$
\end{tabular}

Comment: implications of these and other $\mathrm{S}$ hemisphere data are discussed in Section IV.

\section{VINTAGE WINE SAMPLES}

Additional measurements of atmospheric $\mathrm{C}^{14}$ concentrations in $\mathrm{S}$ hemisphere in the 20th century were made through continuing wine analyses previously reported (Farmer et al., 1972). Grapes were picked in March of the year of production of each wine sample after ca. 4 to 5 mos. on the vine. All wines were produced from grapes picked at vineyards in the Eden Valley ( $34^{\circ} 34^{\prime} \mathrm{S}$ Lat, $139^{\circ} \mathrm{E}$ Long), New South 
Wales, Australia with the exception of the 1929 and 1941a samples derived from grapes grown in the Murray Region $\left(33^{\circ} 20^{\prime} \mathrm{S}\right.$ Lat, $142^{\circ}$ 30 ' E Long), South Australia.

\section{Vintage wine, Australia series}

\begin{tabular}{lcccc}
\hline Sample no. & Yr. & $\delta \mathrm{C}^{14} \%$ & $\delta \mathrm{C}^{13} \%$ & $\Delta \%$ \\
\hline GU-492 & 1929 & $-1.5 \pm 0.6$ & -30.7 & $-0.4 \pm 0.6$ \\
GU-493 & 1934 & $-3.3 \pm 0.6$ & -28.0 & $-2.7 \pm 0.6$ \\
GU-494 & 1938 & $-3.7 \pm 0.6$ & -30.1 & $-2.7 \pm 0.6$ \\
GU-495 & 1939 & $-1.8 \pm 0.6$ & -25.8 & $-1.6 \pm 0.6$ \\
GU-496 & 1940 & $-1.5 \pm 0.6$ & -26.9 & $-1.1 \pm 0.6$ \\
GU-497 & 1941 & $-2.1 \pm 0.6$ & -28.6 & $-1.4 \pm 0.6$ \\
GU-498 & $1941 \mathrm{a}$ & $-1.0 \pm 0.6$ & -25.3 & $-1.0 \pm 0.6$ \\
GU-499 & 1942 & $-2.2 \pm 0.6$ & -27.0 & $-1.9 \pm 0.6$ \\
\hline
\end{tabular}

III. WHEAT SEED SAMPLES

The survey of 20th century annual $\mathrm{C}^{14}$ levels in $\mathrm{S}$ hemisphere was supplemented by the analyses of Australian wheat seed samples grown in New South Wales (exact location undefined), the 1920, 1921, 1932a, and 1936 samples at the State Research Farm, Werribee (37 $52^{\prime} \mathrm{S}$ Lat, $145^{\circ} 8^{\prime}$ E Long), Victoria and the remaining 1932 sample at the Crop Research Division, DSIR, Lincoln (43 $38^{\prime}$ S Lat, $172^{\circ} 30^{\prime}$ E Long), New Zealand. Calendar year refers to time of harvest.

\section{Wheat seeds, Australasian series}

\begin{tabular}{lcccc}
\hline Sample no. & Yr. & $\delta \mathrm{C}^{14 \%} \%$ & $\delta \mathrm{C}^{13 \%} \%$ & $\Delta \%$ \\
\hline GU-500 & 1910 & $+1.1 \pm 0.8$ & -24.1 & $+1.0 \pm 0.8$ \\
GU-501 & 1915 & $+1.3 \pm 0.5$ & -22.1 & $+0.7 \pm 0.5$ \\
GU-502 & 1919 & $-1.0 \pm 0.6$ & -22.9 & $-1.4 \pm 0.6$ \\
GU-503 & 1920 & $-1.5 \pm 0.8$ & -22.7 & $-2.0 \pm 0.8$ \\
GU-504 & 1921 & $-1.7 \pm 0.8$ & -23.2 & $-2.0 \pm 0.8$ \\
GU-505 & 1925 & $-1.6 \pm 0.6$ & -23.0 & $-2.0 \pm 0.6$ \\
GU-506 & 1932 & $-0.7 \pm 0.6$ & -21.9 & $-1.4 \pm 0.6$ \\
GU-507 & $1932 \mathrm{a}$ & $-0.2 \pm 0.6$ & -22.9 & $-0.6 \pm 0.6$ \\
GU-508 & 1936 & $-0.9 \pm 0.8$ & -23.0 & $-1.3 \pm 0.8$ \\
\hline
\end{tabular}

IV. WOOL SAMPLES

Several sheep's wool samples from Australia were analyzed. The 1922 sample was grown at Harrogate $\left(35^{\circ} \mathrm{S}\right.$ Lat, $139^{\circ} \mathrm{E}$ Long), South Australia, the 1923 and 1924 samples at Native Valley, Nairn $\left(35^{\circ} \mathrm{S}\right.$ Lat, $138^{\circ} 55^{\prime}$ E Long), South Australia and the 1946 and 1947 samples at Robe (37 $10^{\prime} \mathrm{S}$ Lat, $139^{\circ} 45^{\prime} \mathrm{E}$ Long), South Australia. Calendar year refers to time of shearing, each wool sample representing ca. 1 yr growth prior to shearing in the early months of the year. Samples were charred at $500^{\circ} \mathrm{C}$ prior to combustion in the gas preparation system. 


\section{Wool, Australia series}

\begin{tabular}{lcccc}
\hline Sample no. & Yr. & $\delta \mathrm{C}^{14 \%} \%$ & $\delta \mathrm{C}^{13 \%} \%$ & $\Delta \%$ \\
\hline GU-509 & 1922 & $-0.7 \pm 0.6$ & -23.4 & $-1.0 \pm 0.6$ \\
GU-510 & 1923 & $-1.5 \pm 0.6$ & -23.8 & $-1.8 \pm 0.6$ \\
GU-511 & 1924 & $-1.4 \pm 0.7$ & -27.6 & $-0.9 \pm 0.7$ \\
GU-512 & 1946 & $-1.9 \pm 0.6$ & -21.0 & $-2.7 \pm 0.6$ \\
GU-513 & 1947 & $-2.2 \pm 0.7$ & -21.5 & $-2.9 \pm 0.7$
\end{tabular}

Comment: collective results of $\mathrm{C}^{14}$ analyses of tree rings, wines, wheat seeds, and wool from $\mathrm{S}$ hemisphere constitute a detailed series of measurements of annual $\mathrm{C}^{14}$ levels during 20th century. The data indicate a general decrease of ca. $0.05 \%(\Delta)$ per yr to a value of $-2.45 \%$ in 1951-52. No correlation between $\mathrm{C}^{14}$ and sunspot no. is evident and, within statistical error, the decrease is linear. Thus annual fluctuations previously noted in $\mathrm{N}$ hemisphere for this interval (Baxter and Walton, 1971) are probably dampened below detectable levels in S hemisphere.

\section{REFERENCES}

Baxter, M. S., Ergin, M., and Walton, A., 1969, Glasgow University radiocarbon measurements I: Radiocarbon, v. 11, p. 43-52.

Baxter, M. S. and Walton, A., 1970, Glasgow University radiocarbon measurements III: Radiocarbon, v. 12, p. 496-502.

1971 , Fluctuations of atmospheric carbon-14 concentrations during the past century: Royal Soc. [London] Proc., ser. A, v. 321, p. 105-127.

Fairhall, A. W. and Young, J. A., 1970, Radiocarbon in the environment, in: Gould, R. F., (ed.), Radionuclides in the environment: Washington, D.C., Am. Chem. Soc. Pub., p. 401-418.

Farmer, J. G. and Baxter, M. S., 1972, Short-term trends in natural radiocarbon, 8 th internatl. conf. on radiocarbon dating Proc., Lower Hutt, N. Zealand, Oct. 1972 , in press.

Farmer, J. G., Stenhouse, M. J., and Baxter, M. S., 1972, Glasgow University radiocarbon measurements VI: Radiocarbon, v. 14, p. 326-330.

Jansen, H. S., 1970, Secular variations of radiocarbon in New Zealand and Australian trees, in: Olsson, I. U. (ed.), Radiocarbon variations and absolute chronology, 12th Nobel symposium Proc. Stockholm, Almquist and Wiksell, p. 261-270.

Olsson, I. U., Klasson, M., and Abd-el-Mageed, A., 1972, Uppsala natural radiocarbon measurements XI: Radiocarbon, v. 14, p. 247-271. 